\title{
A FORÇA COERCITIVA: Um instrumento a serviço da pax temporalis na civitas, segundo santo Agostinho
}

\author{
Marcos Roberto Nunes Costa
}

SÍNTESE - Baseado no princípio ontológico da vera justitia, ou da "divina ordem", segundo a qual é justo que se "subordinem as coisas somente às dignas, as corporais às espirituais, as inferiores às superiores, as temporais às sempiternas" (Ep., 140), o que resulta, na prática, na subordinação dos governados aos governantes, Agostinho introduz em sua doutrina ético-política o conceito de força coercitiva, como instrumento prático garantidor da ordinata concordia ou pax temporalis, na civitas, de forma que, punido pelo reto castigo, o pecador possa retornar à ordem assim alcançar a vida eterna. Em Agostinho, todas as formas de castigos por ele admitidos não têm um caráter de perseguição, vingança ou sadismo, mas de correção e reintegração do pecador na ordem, por isso devem ser guiados pela caridade.

PALAVRAS-CHAVE - Força coercitiva. Castigo. Justiça. Ordem. Paz. Caridade.
ABSTRACT - With basis on the ontological principle of Vera justitia, or of "divine order", according to which it is fair to "subordinate things only to the worthy ones, the corporal to the spiritual, the inferior to the superior, the temporal to the sempiternal" (Ep. 140), this results, in practice, in the subordination of the governees to the governators, Augustine introduces in his ethical-political doctrine the concept of coercitive force, as the practical instrument that warrants the ordinata concordia or pax temporalis, in civitas, in such a manner, that punished by the straight punishment, the sinner may return to order and so reach eternal life. In Augustine, all forms of punishment by him admitted do not take a character of persecution, revenge or sadism, but of correction and reintegration of the sinner in the order, and, for this reason, punishment must be guided by charity.

KEY WORDS - Coercitive force. Punishment. Justice. Peace. Charity.

Para Agostinho, a ordinata concordia ou pax temporalis está fundamentada no princípio da Vera Justitia, ou da "Divina ordem", segundo a qual é justo que se "subordinem as coisas somente às dignas, as corporais às espirituais, as inferiores às superiores, as temporais às sempiternas" (Ep., 140), o que resulta, na prática, na subordinação das coisas inferiores (os mandados) às superiores (aos que mandam).

Baseado nesse princípio, Agostinho justifica, também, o uso do poder como força coercitiva, seja para prevenir os males ou punir (castigar) os que desrespei-

Doutor. Professor de Fil. Patrístico-Medieval da UNICAP e do INSAF, Líder do Grupo de Estudos e Pesquisas em Filosofia Antiga e Medieval - GEPFAM/UNICAP/CNPq, Presidente da Comissão Brasileira de Filosofia Medieval - CBFM. E-mail: marcosc@unicap.br.

\begin{tabular}{|l|l|l|l|l|l|}
\hline VERITAS & Porto Alegre & v. 51 & n. 3 & Setembro 2006 & p. 5-14 \\
\hline
\end{tabular}


tam a justa ordem, ou a ordinata concordia entre os homens, visto serem esses inclinados ao mal, por conta do pecado original. ${ }^{2}$

Não que o castigo seja um bem em si mesmo, mas, apenas, um instrumento da justiça, pelo qual se aplica o princípio de "dar a cada um o que é seu". Daí que "o jugo da fé impõe-se, com justiça, ao pecador" (De civ. Dei, XIX, 15).

Colocado em tais princípios, defende que, além de ser justo que uns mandem e outros obedeçam, é, também, justo que se castigue o infrator, ou seja, aquele que não quer obedecer ao que manda. Não por puro sadismo do poder, mas com o intuito de corrigir o outro, de trazê-lo de volta à ordem. Nesse sentido, ainda que o castigo o faça sofrer, é uma verdadeira obra de amor [de caridade], um dever, um compromisso com a verdade, pois, "para ser amigo de alguém - diz Agostinho -, primeiro é preciso ser amigo da verdade" (Ep., 155,1). É a chamada "pena emendatória" ${ }^{3}$ citada por Agostinho em diversos de seus escritos, como, por exemplo, na Regra, escrita aos monges, em que prescreve o reto castigo ao religioso culpado:

[...] e, uma vez reconhecido culpado, tal religioso deverá submeter-se à pena emendatórtia, determinada a critério do Prior ou do Sacerdote encarregado da comunidade (Reg. IV, 27)

Igualmente, no Tratado Sobre a Cidade de Deus, referindo-se ao caso da família, primeira célula da sociedade, diz:

Se, em casa, alguém turba a paz doméstica, por desobediência, é, para sua própria utilidade, corrigido com a palavra ou com qualquer gênero de castigo justo e lícito, admitido pela sociedade dos homens, para reuni-lo à paz de que se afastara (De civ. Dei, XIX,16).

Portanto, a correção/punição não deve ter um caráter de vingança ou crueldade, mas de misericórdia para com o pecador e remédio preventivo contra o mal: amor para com o pecador, para que se corrija e volte ao seio da comunidade. Visto sob esse prisma, e baseado no princípio de que "é melhor prevenir do que remediar", Agostinho diz que aplicar o castigo é, antes, um dever, uma responsabilidade, do que uma ação maldosa. E quem não o fizer, comete pior ato do que se castigasse. É o que nos diz, na continuidade da citação anterior:

Não é amável quem ajuda outro a perder um bem maior. Da mesma forma, não é isento de culpa quem, por não ajudar o outro, deixa-o cometer um pecado mais grave. A obrigação de todo homem bom é, além de não ferir ninguém, evitar que alguém fira a

Relacionando este estado de decadência do homem, que o leva a cometer o mal e a necessidade da força coercitiva, diz GARCIA-JUNCEDA, 1988, p. 190: "Para Agostinho, enquanto o amor de Deus não substitua o egoísmo, ordem, paz e justiça serão impossíveis por convicção e só realizáveis por coação legal".

Segundo BOFF, 1988, p. 121-22, a expressão "pena emendatória" foi cunhada por Agostinho e tem uma função purificadora, corretiva ou salutar, uma vez que leva o outro a tornar-se melhor, "isto quer dizer que o castigo tem por função, não o esmagamento do culpado, mas, ao contrário, seu melhoramento, seu crescimento humano". Por isso, Agostinho é totalmente contra a pena de morte e/ou mutilações corporais, visto que, se o objetivo da pena é corrigir o pecador, a pena de morte não dá essa chance ao pecador. 
si mesmo, chegando, se for necessário, a castigá-lo. Dessa forma, quem foi punido é beneficiado, e os que vêem tomam para si a experiência (De civ. Dei, XIX, 16). ${ }^{4}$

Assim, Agostinho mostra que ser caridoso para com alguém não significa, apenas, ser condescendente, passando a mão sobre a cabeça, mas, muitas vezes, severo para com ele, conforme vemos no Comentário à $1^{a}$ Epístola de São João:

Se quereis conservar a caridade, irmãos, tratai de esquecer que a ela basta certa mansidão, indolência e moleza. Não! Não é assim que ela é conservada. Não [...] penseis que amais vosso filho, porque não o corrigis ou castigais [...]. Isso não é caridade, é tibieza. Que a caridade seja ardente para corrigir, para repreender. São corretos os costumes de teu filho? Que te causem alegria! São maus? Então, sejam repreendidos, corrigidos! (Inarr. in $1^{a}$ Ep. Joan., 7, 11) ${ }^{5}$

E o mesmo que vale para a Família, vale para a vida em sociedade, em termos gerais (a Civitas), quando recomenda o uso da força coercitiva, tanto para prevenir (pelo medo) quanto para punir (castigo) os cidadãos, visto defender que há nos homens uma inclinação natural para o desrespeito à ordem, em conseqüência do pecado original. Aliás, esse é, para Agostinho, um dos principais motivos, da necessidade da Civitas, enquanto organização governamental (o Estado hoje), capaz de controlar a maldade humana, pois se os homens fossem isentos de tal inclinação, viveriam, harmoniosamente, sem a necessidade da presença da Civitas. Daí dizermos que, em Agostinho, o Estado [Civitas] é filho do pecado ou só existe o Estado [Civitas], porque o homem é pecador. É o chamado "mal necessário". Ou seja, antes do pecado original, no estado de inocência, não havia necessidade do Estado [Civitas], bem como, no futuro, na Escatologia, não há necessidade dele, conforme acentua o comentador Gaetano Lettieri:

É muito importante sublinhar como, para Agostinho, a Cidade política - qualquer grupo de indivíduos estruturados em uma hierarquia de poderes e de funções sociais não seja de fato uma 'instituição natural', quanto por 'natureza' se entenda a verdadeira essência do homem, que, para Agostinho, é aquela própria do estado edênico. O binômio 'imperare-oboedire' (XIX, 13,1) não tem sentido nem na sociedade edênica, nem na Cidade Celestial: Adão e Eva viviam, antes do pecado, em uma fida societas, em uma pura e transparente identidade de vontade, e, por isto, não havia necessidade,

\footnotetext{
Igualmente, diz em sua Regra, aconselhando os seus irmãos confrades: "Não serás inocente, se, por calar-te, permites que se percam irmãos a quem poderias corrigir com um alerta. Se um irmão teu tivesse no corpo um ferimento e quisesse ocultá-lo por medo do curativo, não serias cruel, calando-te, e misericordioso, manifestando-te? Muito maior motivo tens para denunciar seus erros, a fim de que a ferida não cresça em seu coração!" (Reg., 7).

5 E, mais adiante: "Não ames o vício por causa do homem, nem odeies o homem por causa do vício. O homem é teu próximo. O vício é o inimigo do próximo. Logo, ama o amigo e odeia o seu inimigo" (Enarr. in $1^{\mathrm{a}} \mathrm{ep}$. Joan., 90, 2). Igualmente, noutros locais: "Nem sempre o que é indulgente conosco é nosso amigo, nem o que nos castiga, nosso inimigo. São melhores as feridas causadas por um amigo que os falsos beijos de um inimigo. É melhor amar com severidade que enganar com suavidade" (Enarr. in $1^{a}$ Ep. Joan., 9, 17). E noutra Epístola: "És um bom amigo de teus amigos, enquanto és um inimigo de seus defeitos" (Ep., 133, 2); "Serias bom para teu companheiro, se ele, caminhando no escuro, se aproximasse de um abismo e tu ficasses calado? Se não corriges, quando deves, és cúmplice do mal" (Inarr. in PS., 49, 26).
} 
nas suas relações, nem de comandos, nem de leis, enquanto entre eles não havia nem contrastes, nem oposições. ${ }^{6}$

Nesse sentido, apesar de enquadrar-se na visão negativa, o Estado [Civitas] aparece, também, como um remédio contra o pecado, conforme palavras de Giovanni Garilli, interpretando Agostinho:

Sem o pecado, seríamos, de fato, uma sociedade feliz e não turbada pelas paixões: não seríamos um Estado, porque o Estado terreno, assim como é realizado na História, é fundado sobre a violência e sobre o engano, e tem a necessidade de apoiar-se em tribunais, em carneficinas, em torturas. O Estado assim como é é um modo de ser histórico da Cidade do diabo, é obra do pecado e ao mesmo tempo representa um remédio contra os pecados. A sua gênese histórico-natural está ligada à pecaminosidade da natureza humana.?

Nessa perspectiva, como acentua Sergio Cotta, ${ }^{8}$ o Estado [a Civitas] não tem nada de diabólico, antes, pelo contrário, é necessário e útil, como instituição moral capaz de controlar a maldade humana, contrariamente ao que defendem muitos, como, por exemplo, Adriano Tilgher, ${ }^{9}$ que o pensamento de Agostinho era, essencialmente, anti-social, ao negar ou desvalorizar toda e qualquer forma de organização social terrestre, humanamente fundada e supervalorizar uma sociedade espiritual, só possível na Escatologia.

Além disso, há uma terceira concepção de Estado em Agostinho, ao lado daquela negativa que o vê como algo diabólico e esta, mais otimista, como algo necessário e útil, a saber: de um Estado natural, filho da natureza sociável do homem, já apresentada, por nós, anteriormente e evidenciada, aqui, por Miguel Ángel Rossi:

A primeira delas acentua uma valoração pessimista do Estado por parte do Hiponense, enquanto o mesmo é percebido como produto do pecado. A segunda, em estreita oposição à primeira, parte de uma valoração positiva do Estado, enquanto esse pode interpretar-se como o reflexo da sociabilidade da natureza humana. Nessa perspectiva, a ênfase recai sobre o caráter natural do Estado como dimensão social. A terceira considera o Estado como produto do pecado. Coincide com a interpretação pessimista, po-

\footnotetext{
LETTIERI, 1988, p. 104.

GARILLI, 1957, p. 165. E, completa, mais adiante, p. 180: "Sem o pecado, a organização política seria diversa daquela atual; mas, havendo o pecado, o homem não merece um Estado diverso daquele que tem. Como para os outros Padres, assim também para Agostinho, o Estado representa "poena et remedium peccati'.". Igualmente, apontam, em Agostinho, a necessidade da Civitas lo Estado], como promotora da paz temporal os comentadores: PICCOLOMINI, 2000, p. 159: "No peregrinar terreno das 'duas Cidades', aquela celestial e esta terrestre, a Cidade de Deus se apropria da paz da Babilônia": GOISIS, 2000 p. 161: "Com uma afirmação que soa paradoxal Agostinho sustenta que, enquanto as 'duas Cidades' estiverem mescladas, também os bons se servem da paz da Babilônia"; MARKUS, 2001, p. 535: "A sociedade organizada, politicamente, e as relações institucionais, como a sujeição à autoridade, a escravatura, o governo e a propriedade de bens são consequiências do pecado original, porém existem, atualmente, com o fim de proporcionar condições para o exercício da virtude". Igualmente, COLEMAN, 1989, p. 53, diz: "É em conseqüência do pecado de Adão, herdado pelo homem, que ele precisa de governos, propriedades privadas, leis coercitivas, tudo isso para manter a paz que ele tanto procura, mas não consegue alcançar sozinho".

Cf. COTTA, 1960, p. 119 e 133.

Cf. TILGHER, apud BRUCCULERI, 1945, p. 14
} 
rém diferentemente da primeira, e em sintonia com a segunda, crê que o Estado funciona como uma espécie de remédio e reparação ao estado de pecado. ${ }^{10}$

Ou seja, não devemos esquecer que, anteriormente, Agostinho colocava o Estado como uma extensão natural da família, ao dizer que é ínsito à natureza humana o viver em sociedade, e que, ainda no estado de inocência, o homem procurou viver em sociedade organizada.

Por isso Agostinho tem defendido, com grande força, a "necessidade do Estado [a Civitas]", e, dentro desse, o poder coercitivo do exército (soldados), como instrumento do poder em defesa da paz.

Dentro desse espírito, contrariamente aos maniqueus que viam os soldados romanos como "filhos de Satanás", Agostinho os vê como amigos da Civitas. E como cabe a esses promover a paz temporal, com vista à vida eterna, Agostinho chega a chamá-los de "soldados de Cristo", não no sentido em que os entenderam, mais tarde, "as cruzadas", mas como protetores da doutrina de Cristo, em nível individual e coletivo. Não qualquer soldado, mas o bom soldado (cristão), que luta contra o inimigo de forma sóbria, equilibrada, não com ódio, mas com o desejo de trazer o inimigo para Cristo. É por isso que faz boa amizade com o general Bonifácio e o aconselha a não deixar a função, quando esse pensa em abandonar as fileiras do exército.

E dentre os castigos sociais, admitidos pela sociedade e justamente aplicados para preservação da ordinata concordia, está a escravidão.

Entretanto, vale salientar, Agostinho não justifica a escravidão como um direito natural, como o fez, por exemplo, a tradição judaica e aquela grego-romana, e nessa, especialmente, Aristóteles. ${ }^{11}$ Para ele, Deus não criou os homens para que dominassem uns aos outros. O domínio dos homens se dirige, exclusivamente, aos animais, conforme vemos no Tratado Sobre a Cidade de Deus: "Deus quis que o homem, ser racional, criado à sua imagem, não dominasse senão sobre os seres irracionais: não o homem sobre o homem, mas o homem sobre o animal" (De civ. Dei, XIX, 15).

Para Agostinho, se a escravidão existe, deve ser vista como um castigo inflingido à humanidade por conta de seus pecados, conforme diz em uma passagem da supracitada obra: "A primeira causa da servidão, é, pois, o pecado, pelo qual um homem é submetido ao homem em uma condição de dependência [...]" (De civ. Dei, XIX, 15). ${ }^{12}$

Além de um castigo, a escravidão, como os demais castigos sociais, é uma forma de expiação ou remédio contra o pecado, conforme acentua Remo Piccolomini:

Pelo direito natural, os homens são todos iguais, portanto, a escravidão é exclusa. Porém a escravidão, em si condenável, pode vir a ser um meio de purificação. O cristia-

ROSSI, 2000, p. 137

A esse respeito diz ROLAND-GOSSELIN, 1925, p. 169: "A propósito da legitimidade da escravidão, se pode dizer que o pensamento de Agostinho é o ponto de convergência da tradição judaica e daquela grego-romana. Ora, em ambas tradições, a escravidão era tida como instituição natural".

12 A esse respeito, diz GARCIA-JUNCEDA, 1988, p. 189: "Agostinho assinala que a palavra servo a mereceu, o homem, não por natureza, mas pelo pecado. Daí que, a rigor, nada está legitimado para chamar ou fazer alguém servo seu em nada. Somente ao pecador, em relação a Deus, é atribuível tal categoria". 
nismo afirma que a pior escravidão é aquela do pecado, que se encarna na cupidez do poder, como acontece nos tiranos. Concluindo, pode-se dizer que o cristianismo faz da escravidão uma conseqüência do pecado e, portanto, um ato de reparação, pela qual a transforma em livre exercício de amor. ${ }^{13}$

Portanto, a escravidão não é um estado de natureza, mas uma condição social, uma decorrência da perda da natureza primitiva, por parte do homem, que, depois do pecado, tornou-se corrompida. Daí dizer Jean Jacques Chevallier que, em Agostinho, a escravidão "é natural em segundo grau, em relação à natureza corrompida e desviada do homem, depois da queda". ${ }^{14}$ Assim sendo, por não ser natural, poderá [e deverá] acabar a qualquer momento, quando do desaparecimento da soberba dos próprios homens, que leva a escravizar uns aos outros, e todos, aos pecados.

Assim sendo, entendemos que, no tocante à escravidão, Agostinho, apresenta uma posição ambígua: por um lado, a admite, como, ao mesmo tempo, fruto e remédio contra o pecado, tornando-se um conservador, por outro, tira o seu caráter natural, transformando-a numa condição, momentânea e superável. Por isso, prega uma necessidade de superação desse estágio da humanidade, quando todos serão iguais em Cristo. O que torna sua posição revolucionária, não no sentido moderno da palavra, mas, pelo menos, em relação aos antigos, como, por exemplo, Aristóteles, para o qual a escravidão é algo natural e necessário, conforme acentua A. Brucculeri:

Como todos os Padres da Igreja, que têm tratado desse assunto, ele está bem longe de propor a abolição de um instituto que está a fundo penetrado no mecanismo econômicosocial da Antigüidade, mas está pelo menos distante da absurda concepção aristotélica. ${ }^{15}$

Tanto é assim que, enquanto representante do poder judiciário na sua diocese, uma vez que cabia ao Bispo a função de juiz de direito da diocese, conforme veremos mais adiante, quando falarmos das relações de ajuda mútua entre Igreja e Império, Agostinho, em Epístola de número 10, intercedeu junto à Corte para que promulgasse uma lei dando aos Bispos o direito de libertar os escravos, submetidos a esse regime, em situações injustas, tais como crianças, idosos, fruto de tráficos, etc. Esse documento foi promulgado pelo imperador Honório e se chamava manumissio in ecclesia, o qual dava, à Igreja, o poder de fiscalizar e julgar os casos de escravidão, ditos injustos. ${ }^{16}$ Além disso, em 401, os Bispos da África,

13 PICCOLOMINI, 2000, p. 122-23.

CHEVALLIER, 1982, p. 178. Igualmente, diz RIST, 1997, p. 302-3: "Na concepção agostiniana, a escravidão, claramente, um primeiro exemplo de 'dominação', é o efeito da queda, parte da nossa condição pela [...]. E por escravidão Agostinho não entende, apenas, a supremacia de um indivíduo sobre o outro, mas aquela de um povo ou de uma nação sobre a outra".

15 BRUCCULERI, 1945, p. 119. Igualmente, diz VAN DER MEER, 1965, p. 190-91: “A escravidão subsistia, como base que era, inatingível, da civilização antiga. Como Paulo e como todos os Padres da Igreja, Agostinho se preocupava mais em melhorar ou elevar as relações existentes entre senhores e escravos, que de predicar uma reconstrução da ordem social, empresa em que nada pensava e era, do ponto de vista técnico, irrealizável naquele tempo [...]. Sem embargo, a essa concepção se opunha, com a doutrina expressa de que a subordinação de um ser racional a outro era castigo do pecado original, não conseqüência da natureza primitiva e íntegra".

16 A esse respeito, cf. DODARO, 2001, p. 677-678. Segundo VAN DER MEER, 1965, p. 190, a manumissio, também dava, aos Bispos, o poder de proclamar livres os escravos que eram libertos por li- 
dentre eles Agostinho, em Concílio, apelaram ao Imperador, para que nomeasse, em cada cidade, um defensor civitatis, que, segundo Robert Dodaro,

era um funcionário imperial cuja tarefa consistia em proteger os direitos que os Editos imperiais garantiam a todos os cidadãos, mas que os pobres não conheciam ou não eram o suficiente poderosos para fazer valer, frente às injustiças cometidas por mais poderosos existentes nas Cidades. ${ }^{17}$

Ou seja, o defensor civitatis era uma espécie de advogado público dos pobres, com a responsabilidade de vigiar e fazer valer as leis imperiais em favor dos mesmos.

Além disso, usava de seu prestígio para denunciar, principalmente, em Sermões (por exemplo, 21,6; 356, 3-70), as situações de miséria em que se encontravam os escravos libertos, apelando aos cristãos, para que os ajudassem com trabalho e comida, bem como abrigando-os em seu mosteiro, até encontrarem trabalho.

Agostinho afirma que as relações de poder, dentre elas as relações patrãoservo, devem ter, como princípio, a caridade, sem a qual o poder não será justo, ou seja, "que não mande por desejo de domínio, mas por dever de tornar-se útil, não por orgulho de reinar, mas pelo desejo de prover" (De civ. dei, XIX, 14).

Para Agostinho, a legitimidade do poder está na sua relação com Deus, de quem provém todo poder: "Não há autoridade que não venha de Deus" (Rm 13,1.

Se, por conseguinte, se rende culto ao Deus verdadeiro, servindo com sacrifícios sinceros e bons costumes, é útil que os bons reinem por muito tempo e onde quer que seja. $\mathrm{E}$ isto é verdade tanto para os governantes como para os governados. Quanto a eles, a piedade e a bondade, grandes dons de Deus, lhes bastam para felicidade verdadeira, que, se merecida, permite a gente viver bem nesta vida e conseguir depois a vida eterna (De civ. Dei, IV, 3).

Assim sendo, Agostinho faz uma estreita relação entre o uso do poder e a caridade, ${ }^{18}$ ao dizer que

Nada é mais feliz para os seres humanos do que o fato de virem a obter o poder, por bondade de Deus, homens que vivem bem, dotados de uma verdadeira piedade [...] (De civ. Dei, V, 19).

\section{E acrescenta:}

Quem não é cidadão da Cidade Eterna, que em nossas Sagradas Letras chama-se Cidade de Deus, é mais útil à Cidade terrena, quando tem, pelo menos, essa virtude de que se tem necessidade. Os verdadeiramente piedosos, que à vida moral unem a ciência de reger os povos, constituem verdadeira bênção para as coisas, se, por misericór-

\footnotetext{
vre e espontânea vontade dos senhores, os quais eram conduzidos pela mão pelo senhor, que os apresentava ao Bispo, que pronunciava as seguintes palavras: "Dou-lhe a liberdade, pois tens servido em tudo fielmente". E a Igreja incentiva tal prática que era vista como um ato virtuoso por parte do senhor, que devia ser seguido pela aristocracia.

DODARO, 2001, p. 679. Ainda segundo esse comentador, o defensor civitatis era eleito pelos cidadãos e nomeado pelo Prefeito. Agostinho faz menção a tal cargo no Sermão 22, 2 e na Epístola 302, 17.

${ }_{18}$ A caridade, ou o amor, princípio regulador de todas as ações humanas, é outro grande tema da Filosofia agostiniana. Para um maior aprofundamento, recomendamos as obras específicas: ARENDT, 1997, 189 p. e COMBÈS, 1934, 321 p.
} 
dia de Deus, gozam do poder. Tais homens, sejam quais forem as virtudes que podem ter nesta vida, atribuem-nas à graça de Deus [...] (De civ. Dei, V, 19).

E Agostinho vê, em sua época, muitos homens bons (cristãos) em meio aos negócios públicos, como, por exemplo, o Procônsul Donato, ${ }^{19}$ um homem educado, culto, cristão fervoroso, preocupado com questões filosóficas e teológicas, que cumpria seus deveres administrativos com espírito de justiça e de clemência. É o que diz em Epístola:

Quanta integridade nos seus costumes! Que fidelidade na amizade! Que zelo pela doutrina de Cristo! Que sinceridade nos seus sentimentos religiosos! Que castidade no matrimônio! Que equilíbrio nos seus juízos! Que tolerância para com seus inimigos, e para com os amigos aquela amabilidade! Quanta humildade mostrou para com os santos, quanta caridade para com todos, quanto zelo para cumprir o bem, quanta dor pelos próprios erros! (Ep., 151, 8).

Claro que nem todos os funcionários públicos tinham essa qualidade. Já em 390, muito antes de escrever o Tratado Sobre a Cidade de Deus, Agostinho, apesar de elogiar o amor patriótico do pagão Nectário, Governador de Calama, preocupado "em deixar, ao morrer, sua pátria incólume e florescente" (Ep., 90), lamentava faltar-lhe o preceito da "divina caridade", a única capaz de garantir a "verdadeira felicidade" dos cidadãos, que não é senão levá-los a alcançar a pátria celeste. Por isso, recomenda:

Também pelos serviços prestados à pátria terrena, se fizeres com amor veraz e religioso ganharás a pátria celeste [...] desse modo, proverás, de verdade, ao bem de teus concidadãos, a fim de fazê-los usufruir, não da falsidade dos prazeres temporais, nem da funestíssima impunidade da culpa, mas da graça da felicidade eterna. Suprimam-se todos os ídolos e todas as loucuras, convertam-se as pessoas ao culto do verdadeiro Deus e a pios e castos costumes; e então ver-se-á a tua pátria florir não segundo a falsa opinião dos estultos, mas segundo a verdade professada pelos sábios, quando essa pátria, em que nasceste para a vida mortal, será uma porção daquela pátria para a qual se nasce, não com o corpo, mas pela fé, onde [...], após o inverno cheio de sofrimentos desta vida, florescerão na eternidade que não conhecem ocaso [...]. Pois, o amor mais ordenado e mais útil pelos cidadãos consiste em levá-los ao culto do sumo Deus e à religião. Esse é o amor verdadeiro e pio da pátria terrestre, que te fará merecer a pátria celeste (Ep., 104).

Por fim, um último aspecto do poder, apontado e, largamente, defendido por Agostinho é a questão do poder, enquanto serviço. Para ele, toda autoridade vem de Deus que a concede aos homens, não para proveito próprio, mas para servir aos demais. Daí recomendar, para todos aqueles que exercem cargos de autoridade, sejam religiosos ou civis, a máxima de que "presidir é servir".

E tal regra tomava para si, enquanto autoridade religiosa, dizendo, por diversas vezes, que seu cargo de Bispo era antes um serviço que uma honra, conforme aparece, claramente, no Tratado Sobre a Cidade de Deus: "Bispo é um título de

19 McNAMARA, 2000, p. 168-176, ao mostrar que Agostinho era um homem de grandes amizades, dedica grande espaço para falar da sua amizade com os funcionários do Império. Além de Marcelino, relaciona uma série de outros homens, e com quem trocava correspondência: Olímpio, Primeiro-Ministro do Imperador (Ep., 96 e 97); Macedônio, Governador-Geral da África (Ep., 112); Ceciliano, Comissário Imperial (Ep., 151); Os Condes Valério e Dario (Ep., 200; Ep., 229). 
serviço, não de honra" (De civ. Dei, XIX, 19). ${ }^{20}$ E radicalizava seu pensamento, ao ponto de não considerar Bispo (ou qualquer outra autoridade), a quem se aproveitava do cargo para presidir, e não para servir. Por isso o filósofo Guilherme de Ockham, mais tarde, no auge da crise política entre o papa João XXII e o rei Luís da Baviera, ao criticar a idéia de que o Papa reunia em si a "plenitude do poder espiritual e temporal", ou para mostrar que o principado papal foi instituído em vista do bem comum dos súditos e não para honra ou proveito próprio de quem quer que seja, utilizando as [supostas] palavras de Agostinho, que, comentando as palavras do Apóstolo "quem não entra pela porta" (Jo 10, 1), teria dito:

Quem não 'entra pela porta', mas sobe 'por outra parte', isto é, quem não entra pelo chamado do povo, pela eleição dos irmãos, pela provisão de Cristo, mas por prêmio ou pela força dos parentes ou do poder, esse não é pastor, mas ladrão e salteador. Demonstra-se, pois, que alguém é pastor somente se guardar as ovelhas, protegendo, defendendo e vigiando, se não procurar os ganhos terrenos, mas os celestes, se não defender os seus interesses, mas os dos outros, de tal modo que não deseje o episcopado pela ambição do dinheiro, mas para aumentar a fé do povo, a fim de que com os fiéis e para eles receba a retribuição eterna; não para ser senhor, mas pai; não para castigar e perseguir, mas para nutrir [...]. Não convém a um Bispo odiar a alguém, mas amar a todos, incentivar os bons, corrigir os maus [...]. Os Bispos não foram constituídos para dominarem sobre o clero, mas para serem modelos de todos e para, com o seu exemplo, edificarem a todos e não perderem ninguém [...]. O Bispo será réu de tantos homicídios quantos forem os que vierem a perder-se por seu mau exemplo ou não os guardar com a sua vigilância. Cristo constituiu-o guardador de almas, não cultivador de campo [...]. Todos os que, abandonando a doutrina de Cristo, dos Apóstolos e dos Santos Padres, vivem ou ensinam de modo diferente, não são Bispos, mas pseudobispos, pois não seguem nem os exemplos nem a doutrina de Cristo. ${ }^{21}$

Como se vê, para Agostinho, todas as instituições da sociedade, dentre elas o poder, têm por fim último fazer arder no coração do homem o desejo expresso no Pai-nosso: "Venha a nós o vosso reino". Por isso, "visto que amar a Deus e amar os homens é a mesma coisa, é necessário que as instituições sociais sejam moldadas pela caridade". ${ }^{22}$

\section{Referências}

AGOSTINHO, Santo. A Cidade de Deus: contra os pagãos. 3. ed. Trad. de Oscar Paes Leme. Petrópolis: Vozes; São Paulo: Federação Agostiniana Brasileira, 1991. v. I, 414; v. II, 589p.

\footnotetext{
${ }^{20}$ Ao que completa: "O bom superior não dá ordens pelo afã do poder, mas por espírito de serviço àqueles dos quais cuida; não por orgulho de ocupar uma posição mais alta que seus súditos, mas por compaixão de si mesmo e deles (De civ. Dei, XIX, 14). E noutros locais: "Um superior, em primeiro lugar, deve estar consciente de que é um servidor. Não deve sentir-se inferior por servir a muitos, quando o próprio Senhor dos senhores não se diminuiu ao fazer-se servo da humanidade" (Serm., 32, 1); "Devo ser solícito principalmente pela Igreja que me foi confiada, de quem sou servidor e a quem desejo não tanto presidir quanto servir" (Ep., 134, 1).

${ }^{21}$ AGOSTINHO, apud OCKHAM, 1988, p. 51. (Obs: Ockham não diz de que a obra extraiu esse trecho, apenas atribui tais palavras a Agostinho, nem nós encontramos tais palavras nas obras agostinianas, daí usarmos a expressão apud).

22 DANIEL-ROPS, 1991, p. 50.
} 
Comentário da primeira epístola de são João. Trad. introd. e notas de Nair de Assis Oliveira. São Paulo: Paulinas, 1989. 219 p.

Enarraciones sobre los salmos ( $\left.3^{\circ}\right)$. In: Obras completas de san Agustín. Ed. bilíngue. Trad. de Balbino Martin Perez. Madrid: La Editorial Católica/BAC, 1966. Tomo XXI, 1033p.

. Enarraciones sobre los salmos (4 $4^{\circ}$ ). In: Obras completas de san Agustín. Ed. bilíngue. Trad. de Balbino Martin perez. Madrid: La Editorial Católica/BAC, 1967. Tomo XXII, 948p.

- Escritos vários $\left(2^{\circ}\right)$ : Regla a los siervos de Dios - Las retrataciones. In: Obras completas de san Agustín. Ed. bilíngue. Trad. introd. y notas de Teodoro C. Madrid. Madrid: La Editorial Católica/BAC, 1995. Tomo XL, 1004p.

ARENDT, Hannah. O conceito de amor em santo Agostinho: ensaio de interpretação filosófica. Trad. de Alberto Pereira Dinis. Lisboa: Instituto Piaget, 1997, 189p.

BOFF, Clodovis. A via da comunhão de bens: a Regra de Santo Agostinho comentada na perspectiva da teologia da libertação. Petrópolis: Vozes, 1988, 197p.

BRUCCULERI, A. Il pensiero sociale di s. Agostino. Roma: Edizione "Cività Cattolica", 1945, 404p.

BRUYNE, Edgar. San Agustín: el orden universal. In: —_ . Historia de la estetica: la Antiguidad cristiana y la Edad Media. Trad. Armando Suarez. Madrid: La Editorial Católica , 1963, vol. II, p. 296-305.

BURT, Donald X. Paz. In: FITZGERALD, Allan D. (Dir). Diccionario de san Augustín. Trad. de Constantino Ruiz-Garrido. Bugos: Editorial Monte Carmelo, 2001, p. 1009-1014.

CHEVALLIER, Jean-Jacques. As Duas Cidades: santo Agostinho e sua influência. In: —_ . História do pensamento político: da Cidade-Estado ao apogeu do Estado-Nação monárquico. Trad. de Roberto Cortes de Lacerda. Rio de Janeiro: Guanabara/Koogan, 1982. Tomo 1, p. 173-192.

CILLERUELO, Lope. Comentario a la regra de san Agustín. Valladolid: Estudio Agustiniano, 1994. 597p.

COLEMAN, Janet. Santo Agostinho: o pensamento político cristão no fim do Império Romano. In: SALOMÃO, Jaime (Org.). O pensamento político de Platão à OTAN. Trad. de Talita Macedo Rodrigues, Int. de Brian Redherd. Rio de Janeiro: Imago Editora, 1989, p. 45-61.

COMBÈS, Gustave. La charité d'après saint Augustin. Paris: Desclée de Brouwer, 1934, 321p.

COTTA, Sergio. La città politica di sant'Agostino. Milano: Edizioni di Comunità, 1960, 173p.

DODARO, Robert. La Iglesia y el Estado: la jurisdicción civil del obispo. In: FTTZGERALD, Allan D. (Dir). Diccionano de san Augustín. Trad. de Constantino Ruiz-Garrido. Bugos: Editorial Monte Carmelo, 2001, p. 674-677.

GARCIA-JUNCEDA, Jose Antonio. La sociedad y la paz. In: —_. La cultura cristiana y san Agustín. Madrid: Editorial Cincel, 1988, 205p. (Serie Historia de la Filosofía, n. 7).

GARILLI, Gionanni. Aspectti della filosofia giuridica, politica e sociale di s. Agostino. Milano: Dott. A. Giuffrè - Editore, 1957, 302p.

GOISIS, Giuseppe. La guerra, la pace e la Città di Dio: alcune osservazioni sul libro XIX del De civitate Dei. In: PERISSINOTTO, Luigi (Org.). Agostino e il destino dell'Occidente. Roma: Editrice Carocci, 2000. p. 159-184.

LETTIERI, Gaetano. Il senso della storia in Agostino d'Ippona. Roma: Edizione Borla, 1988, 346p.

McNAMARA, Marie Aquinas. L'amicizia in s. Agostino. Trad. di Sante Celiberti e Carla Giuggioli. Milano: Àncora Editrice, 2000, 240p.

MARKUS, Ética social. In: FITZGERALD, Allan D. (Dir). Diccionario de san Augustín. Trad. de Constantino Ruiz-Garrido. Bugos: Editorial Monte Carmelo, 2001, p. 535-536.

OCKHAM, Guilherme de. Brevilóquio sobre o principado tirânico. Trad. de Luis Alberto De Boni. Petrópolis: Vozes, 1988, 194p.

PICCOLOMINI, Remo. Sant 'Agostino: la pace: il libro XIX de la Città di Dio. Roma: Città Nuova, 2000. 165 p. (Piccola Biblioteca Agostiniana, n. 31).

RIST, John M. Individui, instituzioni sociali e vita política. In: —_. Agostino: il battesimo del pensiero antico. Trad. di Elisabetta Alberti. Milano: Vita e Pensiero (Centro di Ricerche di Metafísica dell'Università Cattolica del Sacro Cuore), 1997, p. 267-331.

ROLAND-GOSSELIN, Bernard. La morale de saint Augustin. Paris: Marciel Rivière, Éditeur, 1925, 250p. ROSSI, Miguel Ángel. Agustín: el pensador político. In: BORON, Atilio A. (Org.). La filosofía política clásica: de la Antigüedad al Renacimiento. Buenos Aires: CLACSO, 2000, p. 131-157.

VAN DER MEER, F. San Agustín, pastor de almas. Trad. de Daniel Ruiz Bueno. Barcelona: Editorial Herder, 1965, 766p. 